\author{
Marquette University \\ e-Publications@Marquette
}

College of Nursing Faculty Research and

Publications

Nursing, College of

8-2013

\title{
Concept Analysis of Empowerment from Survivor and Nurse Perspectives within the Context of Cancer Survivorship
}

Teresa Jerofke-Owen

Marquette University, teresa.jerofke@marquette.edu

Follow this and additional works at: https://epublications.marquette.edu/nursing_fac

Part of the Nursing Commons

\section{Recommended Citation}

Jerofke-Owen, Teresa, "Concept Analysis of Empowerment from Survivor and Nurse Perspectives within the Context of Cancer Survivorship" (2013). College of Nursing Faculty Research and Publications. 249.

https://epublications.marquette.edu/nursing_fac/249 


\section{Marquette University}

\section{e-Publications@Marquette}

\section{Nursing Faculty Research and Publications/College of Nursing}

This paper is NOT THE PUBLISHED VERSION; but the author's final, peer-reviewed manuscript. The published version may be accessed by following the link in the citation below.

Research and Theory for Nursing Practice, Vol. 27, No. 3 (2013): 157-172. DOI. This article is (C) Springer Publishing Company and permission has been granted for this version to appear in e-

Publications@Marquette. Springer Publishing Company does not grant permission for this article to be further copied/distributed or hosted elsewhere without the express permission from Springer Publishing Company.

\section{Concept Analysis of Empowerment from Survivor and Nurse Perspectives Within the Context of Cancer Survivorship}

Theresa A. Jerofke

Marquette University, Milwaukee, WI

\section{Abstract}

The liberal usage of the concept of empowerment has led to the development of a broad and ambiguous term. In health care, empowerment is a core principle of patient-centered care that promotes patient engagement in health management. This is an analysis of the concept of empowerment within the context of cancer survivorship using both Rodgers' evolutionary concept analysis and Caron and Bower's dimensional analysis. The dimensional analysis followed the evolutionary concept analysis as the perspectives of patients and nurse providers emerged in the analysis. Data sources included a sample of 249 papers from multiple disciplines covering the period 2000-2013. Empowerment is defined as power-with that is actualized through a beneficial relationship of mutual trust and respect for autonomy that develops within a dynamic and patient-centered 
process. The attributes, along with the antecedents and consequences, provide a foundation for future theory development of empowerment in the context of cancer survivorship. This analysis demonstrated that although nurses and survivors may have a similar definition of the concept of empowerment, the uses and assumptions of that definition may differ. Future studies should be conducted measuring the effectiveness of an intervention that uses the components of the process of empowerment from survivors' perspectives.

The liberal usage of the term empowerment to describe any event in which individuals or groups take control of some aspect of their lives (Malterud, 2010) has led to a broad and ambiguous understanding of the term (McCarthy \& Freeman, 2008). New initiatives within health care reform encourage patient engagement in health management through the process of empowerment as the burden of chronic illness grows; now accounting for $60 \%$ of deaths worldwide (Improving Chronic Illness Care, 2012; National Institutes of Health, 2011). Advances in technology and treatment have resulted in the reconceptualization of cancer as a terminal to a chronic illness, a shift of focus from cancer patients as victims to survivors (National Coalition for Cancer Survivorship [NCCS], 2010), and a consumer movement advocating for improved care strategies for survivors (Hewitt, Greenfield, \& Stovall, 2005). Development and specification of the concept of empowerment within the context of survivorship is needed to provide a foundation for interventions to improve the cancer survivor's experience.

\section{BACKGROUND}

According to the NCCS (2011), patients are cancer survivors from the time of diagnosis until death. Empowerment is a practical way to address the feelings of uncertainty and vulnerability associated with the complexity of treatment that cancer survivors experience (Ganz, 2009; Peck, 2008) because it facilitates patient engagement in care planning and self-management of health (McCorkle et al., 2011) during and after cancer treatment. Although patients are ultimately the ones responsible for engaging in self-management behaviors, it is well-recognized that nurses can strengthen patients' selfmanagement abilities by providing support and guidance (Kawi, 2012; McCorkle et al., 2011).

The World Health Organization (2009) recently rallied for empowerment as a way to advance health promotion efforts and improve health outcomes. The NCCS (2006) urges cancer survivors to become knowledgeable and informed consumers so that they have an understanding of possible late-onset treatment effects, self-management expectations, and surveillance plans (Morgan, 2009). Although survivors are expected to become self-advocates in their care so that they can navigate the complex health care system safely and efficiently (Hagan \& Donovan, 2013), much of the survivorship literature focuses on the content of cancer survivorship care rather than methods providers can use to actively engage survivors in their care (Marbach \& Griffie, 2011). In addition, most of the empowerment literature in the context of cancer survivorship is written from the perspective of the health care provider and fails to recognize how survivors define empowerment. It is important to examine the perspectives of survivors so that care can be targeted to survivors' needs (Mok, 2001).

There have been eight prior concept analyses of empowerment (Ellis-Stoll \& Popkess-Vawter, 1998; Finfgeld, 2004; Gibson, 1991; Hawks, 1992; McCarthy \& Freeman, 2008; Rodwell, 1996; Ryles, 1999; Tengland, 2008) and four concept analyses of cancer survivorship (Doyle, 2008; Farmer \& Smith, 2002; Peck, 2008; Shepherd \& Woodgate, 2010); however, none of the concept analyses placed the concept 
of empowerment within the context of cancer survivorship. Empowerment and cancer survivorship have both been conceptualized as individualized, dynamic processes (Doyle, 2008; Finfgeld, 2004), and although survivorship involves uncertainty and requires self-advocacy, empowerment works to dissolve uncertainty through the realization that one has the capacity and right to take control. The purpose of this concept analysis was to identify the attributes, antecedents, and consequences of empowerment evident in the intersecting perspectives of cancer survivors and nurse providers.

\section{METHOD}

Rodger's (1989) evolutionary approach was selected as the analysis method because the concept of empowerment is context dependent (Rappaport, 1984) and has evolved over time through use in multiple disciplines including social work, psychology, and nursing. Consistent with Rodger's method, the concept of empowerment was chosen, surrogate terms were identified, and the context of cancer survivorship was identified (Rodgers, 2000). The concept of empowerment was also examined within the broader context of chronic illness care to uncover uses of the term within the nurse-patient relationship to develop the concept for application to the context of cancer survivorship, where it has not yet been widely used. The literature was examined using the process of thematic analysis so that the data across perspectives and contexts could be organized into similar ideas or themes. The themes, among the various descriptions of empowerment in the literature, developed into the attributes of the concept of empowerment. Related terms were recorded as they were uncovered during the analysis.

The analysis evolved to include a dimensional analysis following the methods of Caron and Bowers (2000) when differing perspectives of empowerment and survivorship were uncovered between nurses and cancer survivors. Dimensional analyses can be used to "understand the conceptual nature and evolution of concepts, and the fluidity of concepts across perspectives and contexts" (Caron \& Bowers, 2000 , p. 291). The dimensional analysis method guided the analysis in describing the social construction and multiple perspectives of the concept, differentiating the relationship between perspectives, and identifying assumptions. Given the growing expectation that cancer survivors will self-manage their cancer (Hagan \& Donovan, 2013), it is appropriate to update and expand the explorations of uses and applications of the concept of empowerment from the unique viewpoints of both nurses and patients within the context of cancer survivorship, so that it can be used to help develop interventions to strengthen care of cancer survivors and therefore a dimensional analysis was interwoven within the evolutionary analysis. An exemplar was provided to further situate the resulting attributes within the context of cancer survivorship. The analysis then concluded by identifying implications and hypotheses for further concept development.

\section{DATA SOURCES}

The sample for this concept and dimensional analysis consisted of English language written sources published between the years 2000 and 2013. A keyword search of "empowerment" conducted in Cumulative Index to Nursing and Allied Health Literature (CINAHL) yielded 4,814 articles and "survivorship" yielded 1,172. When the two keywords were combined to limit the search results to articles consistent with the goal of the analysis, only 8 articles were identified. When the keyword of empowerment was combined with the keyword "neoplasms," an additional 17 articles were identified. A decision was made to expand the search to include survivorship and the surrogate terms "patient- 
centered care," "self-efficacy," and "patient autonomy." The keyword survivorship was combined with patient-centered care, yielding 10 articles; with patient autonomy, yielding 1 article; and self-efficacy, yielding 5 articles. Because only 41 articles were identified using the earlier searches, a search was conducted in CINAHL combining the keywords empowerment and "chronic disease," and an additional 104 articles were retrieved, 68 of which were relevant to the analysis.

To illuminate the social construction of empowerment through different perspectives and contexts (Caron \& Bowers, 2000), articles were also obtained from other disciplines by searching the keyword empowerment with neoplasm in Google Scholar (496 articles), ProQuest (215 articles), Medline (128 articles), and PsycINFO (32 articles). Abstracts were reviewed for relevance to the purpose of the analysis, ancestral searching of the articles referred to earlier was performed, and ultimately 249 articles were selected for detailed review. The number of articles included in the final analysis from each search are included in Figure 1.

FIGURE 1 Literature search results.

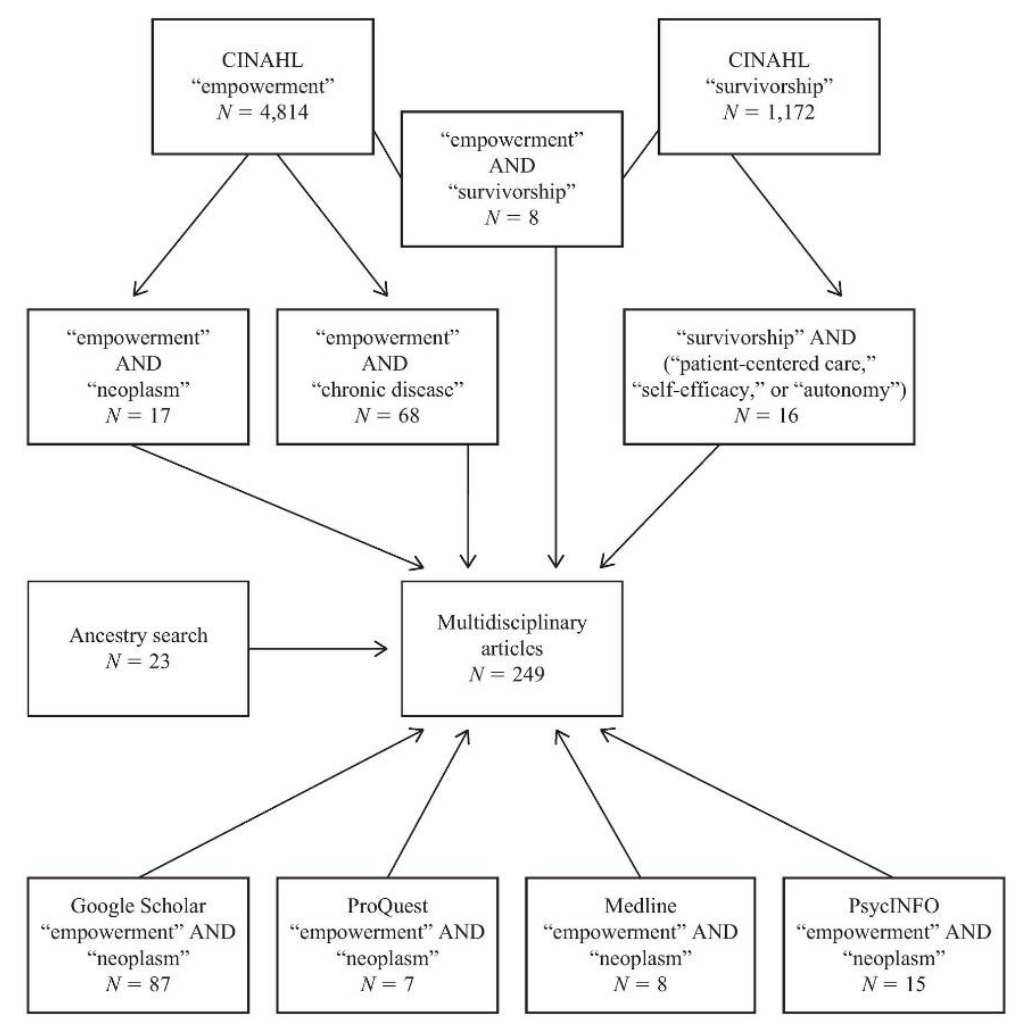

\section{RESULTS}

\section{ATTRIBUTES}

Four attributes of empowerment were identified in the concept analysis. Within each attribute, nurse and survivor perspectives are described.

\section{Dynamic and Patient-Centered Process.}

It is important to envision empowerment not as a dichotomous variable but rather as continuous (Anderson \& Funnell, 2005) and multidimensional (Lewin \& Piper, 2007). Throughout their lives, survivors must navigate periods of being "well" and periods of being "ill" associated with alternating 
periods of feeling empowered and disempowered (Payne, 2007). For example, patients living with head and neck cancer reported they were able to regain control and feel empowered by balancing physical, mental, and emotional health through continual health promotion activities (Bjorklund, Sarvimaki, \& Berg, 2008). Survivors may experience feelings of uncertainty regarding their roles in life that may be dealt with by adapting, reconstructing new life meanings, or withdrawing from certain roles (Little, Sayers, Paul, \& Jordens, 2000).

Empowerment may be influenced by factors such as personal values, religious or cultural beliefs, selfdetermination, past experiences, diagnosis, and social support (Falk-Rafael, 2001; Meyer et al., 2008). The individualized nature of empowerment means that a "one size fits all method" is not acceptable and health care needs to be tailored to fit the needs of the individual, making it a patient-centered approach (Holmstrom \& Roing, 2009). When providing care to cancer survivors, it is necessary to get to know the patient as a person before deciding on a treatment plan. Knowing what the survivor is fearful of or what side effects are not acceptable to the survivor may help determine the direction of the treatment plan (Epstein, Fiscella, Lesser, \& Stange, 2010; Morgan, 2009). Providing patient-centered care to cancer survivors does not mean giving abundant information and expecting survivors to select what is beneficial to them; rather, it is the process of reviewing options to meet health goals and sorting out how those options fit in with the patient's beliefs, values, and culture (Epstein et al., 2010). The lived experience of cancer is unique to each survivor and active engagement by the survivor must be encouraged so that the treatment plan is targeted to each survivor's unique needs (Doyle, 2008).

The way nurses and survivors view the process of empowerment may differ. Nurses may view the process of empowerment as personal growth in patients (Falk-Rafael, 2001) or as a strategy to motivate patients to do what they recommend by focusing on adherence as a metric of empowerment (Christensen \& Hewitt-Taylor, 2006). Nurses may also feel that delivering patient-centered empowering care is burdensome because of the perception that it increases their workload, takes time away from other necessary tasks, requires collaboration with other providers, and may not be billable (Irwin, Klemp, Glennon, \& Frazier, 2011; Morgan, 2009).

Survivors, on the other hand, may view the process as the realization of who they are and what they need or as the opportunity to take control of their lives (Hagan \& Donovan, 2013; van van Uden-Kraan, Drossaert, Taal, Seydel, \& van de Laar, 2009). Survivors have reported feeling more capable and empowered when they were able to change their habits or routines to better meet their needs (Bjorklund et al., 2008). Therefore, patients may feel that the process of empowerment originates from within themselves rather than from the provider (Aujoulat, d'Hoore, \& Deccache, 2007). In a patientcentric view, empowerment has been described as "patient perceptions of access to information, support, resources, and opportunities to learn and grow that enable them to optimize their health and gain a sense of meaningfulness, self-determination, competency, and impact on their lives" (Spence Laschinger, Gilbert, Smith, \& Leslie, 2010, p. 5).

\section{Beneficial Relationship of Mutual Trust and Respect for Autonomy.}

The process of empowerment is transactional, meaning that it is facilitated within relationships (Gibson, 1991; van Uden-Kraan et al., 2009). The nurse has the health information the survivor needs to make informed choices, but the survivor is the expert on his or her body or subjective information (Kaplan \& Frosch, 2005; Kim, Boren, \& Solem, 2001). Communication must flow in two directions, 
making the process mutual or reciprocal (Stang \& Mittelmark, 2010). Nurses must be cognizant not to "empower" a survivor to undertake his or her goals, but rather should make sure the survivor's goals are represented in the plan of care. The role of the nurse in an empowerment model is not to simply change patients' behavior but rather to help patients identify ways to attain mutually agreed-upon goals (Funnell \& Anderson, 2003; Wiljer et al., 2013).

Both nurses and survivors agree that a trusting, respectful relationship is crucial to empowerment (Liu, Mok, \& Wong, 2006; Stajduhar, Funk, Jakobsson, \& Ohlén, 2010) and survivors' concerns need to be voiced so that they can factor into the health care decision making process (Kaplan \& Frosch, 2005). Because of the feelings of vulnerability and uncertainty that frequently occur in cancer survivors, it is important to develop a partnership that demonstrates mutual trust and respect for autonomy (McCorkle et al., 2011). Cancer survivors may feel as though information is being withheld from them because of the life-threatening nature of cancer diagnosis (Anderson, Rainey, \& Eysenbach, 2003). They may also not tell their nurse about some of their concerns or side effects because they do not want to be viewed as bad patients or their treatment to stop (Victorson, Cella, Wagner, Kramer, \& Smith, 2007). Survivors need to feel welcome to share even the smallest of concerns because those concerns could impact their treatment or quality of life in the future (Twomey, 2012; Victorson et al., 2007).

Autonomy will be present in varying degrees depending on the extent to which survivors understand and process information and the extent that they accept the responsibility to take control of their lives (Sinding et al., 2010). In fact, an individual may make the choice to defer decisions to another individual, which is an autonomous act as long as that person is making an informed decision (Anderson \& Funnell, 2010). Some patients may want to be entirely looked after as a means of comfort or protection from the reality of their diagnosis (Faulkner, 2001). For example, over one-third of Korean patients left the decision-making about their terminal cancer to others (Mo et al., 2012). In addition, there is some evidence that shows that survivors' desires for participation in their care may differ based on the type of cancer and stage of disease (Gaston \& Mitchell, 2005).

Respecting patient autonomy may become a dilemma for the nurse if a survivor's choice or decision does not coincide with what the nurse thinks is best for the survivor (Ryles, 1999; Sinding et al., 2010). If a difference in knowledge causes a discrepancy in goals between the nurse and survivor, it is the nurse's responsibility to share that knowledge with the survivor so that informed decision making can occur (Sinding et al., 2010; Tveiten \& Meyer, 2009). The guidelines for the treatment of cancer are often complex and although patient autonomy for decision making regarding treatment options should be respected, survivors often desire the guidance of providers when making difficult decisions (Mendick, Young, Holcombe, \& Salmon, 2010). Providing survivors with justification of why a certain treatment or surveillance measure is being prescribed help survivors feel ownership in the careplanning process (Mendick et al., 2010).

\section{Power-With.}

Power has been defined as "the ability to get things done, to mobilize resources, to get and use whatever it is a person needs for the goals he or she is attempting to meet" (Kanter, 1993, p. 166). Most agree that empowerment is not about giving or taking power but rather is a dynamic entity, not fixed in either the nurse or patient, but rather changing form based on the context (Bradbury-Jones, 
Sambrook, \& Irvine, 2008). Power is not about oppression but rather "produces things, induces pleasure, forms knowledge, produces discourse" (Foucault \& Gordon, 1980, p. 119). In this view, power in the context of health care would be something that flows between the nurse and the patient through the sharing of knowledge and the facilitation of action.

Laverack (2007) described three types of power in health care: power-over, power-from-within, and power-with. Providers are often viewed as having power-over because they have been professionally trained and have access to resources (Laverack, 2007)-also known as expert power. Power-over can either be used to exert control over the patient such as in a paternalistic relationship or can be used to increase the patient's power-from-within in an empowering provider-patient relationship. Powerfrom-within develops internally in patients because of a sense of confidence or strength, and is demonstrated when patients start to sense an opportunity for control over their lives (Rissel, 1994) and begin using knowledge as a tool of power (Christensen \& Hewitt-Taylor, 2006). Therefore, in an empowerment model, the provider uses power-over to share expert knowledge in an interactive process where the patient uses power-from-within to assert personal goals, circumstances, beliefs, and solutions.

The process of integrating power-over with power-from-within is called power-with. The sharing of knowledge, goals, and beliefs that is demonstrated through power-with is an essential part of an empowering discourse between providers and patients. The development of power-with involves choosing the topic of discussion, giving opportunities to participate in the discourse, and giving the patient an opportunity for reflection (Virtanen, Leino-Kilpi, \& Salanterä, 2007). Power-with is evident when patients feel they have enough knowledge and skill to make choices and take action with respect to their health management.

The development of power-with is an integral component of cancer survivorship care. Cancer survivors were found to have higher levels of psychological distress than individuals with other chronic conditions (Kaiser, Hartoonian, \& Owen, 2010), which was amplified further if the survivors had fewer resources to manage their health. Nurses may therefore believe that survivors could feel overwhelmed if they are given too much information about their cancer and treatment options or that survivors with more advanced cancer will not want to be as involved in their care. On the contrary, cancer survivors have been shown to perceive a higher quality of life when they feel knowledgeable about their treatment options and when they become active participants in their care (McCorkle et al., 2011; Pedro, 2001) and survivors with advanced cancer still wished to remain independent and in control of their lives (Johnston \& Smith, 2006). Survivors view knowledge as a tool or way to cope with their diagnosis and use it to make decisions and plan for the future (Marbach \& Griffie, 2011). In addition, although providers may want to plan long-term goals for the survivor, survivors rely on short-term goals and may favor living one day at a time (Bulsara, Ward, \& Joske, 2004).

For empowerment to occur, the perceived expert must be willing to step down from the controller role, have an adequate amount of time to actively engage the survivor in treatment planning, and provide the survivors with the necessary resources to make informed decisions (Sainio, Eriksson, \& Lauri, 2001). With the promotion of patient engagement in national health care priorities, nurses must become more comfortable with survivors playing active roles in their care and should encourage patient engagement rather than alienate empowered patients or call them difficult (Johnson, 2011; 
Nyatanga \& Dann, 2002). Nurses and survivors may also have differing views about what behaviors are empowering. For example, nurses may feel that their knowledge sharing is the facilitator of empowerment, whereas survivors may find that the presence of support, time spent with them, and resources are key facilitators to their empowerment (Sainio et al., 2001). Encouraging survivors to interact with each other amplifies feelings of empowerment because survivors reported that Online support groups improved self-confidence in their treatment, enhanced their self-esteem, and strengthened their relationship with their providers (Bartlett \& Coulson, 2011).

\section{DEFINITION}

The identification of these attributes and how they were related to each other resulted in the definition of empowerment as power-with that is actualized through a beneficial relationship of mutual trust and respect for autonomy that develops within a dynamic and patient-centered process. This definition emerged from within the context of cancer survivorship but may also be relevant for other chronic illness experiences.

\section{ANTECEDENTS AND CONSEQUENCES}

The identification of antecedents, "phenomena found to proceed an instance of the concept" and consequences, phenomena that "follow an occurrence of the concept" present further clarity about a concept (Rodgers, 1989, p. 334). Before empowerment can occur, survivors need to realize that they have a right and are capable of making decisions about their care (Christensen \& Hewitt-Taylor, 2006). There also has to be motivation for knowledge, control, or action (Aujoulat et al., 2007). If an individual does not believe he or she can play an active role in his care and make decisions, the motivation or drive to play an active role will be diminished. Lastly, patients must have a diagnosis of cancer before empowerment in cancer survivorship can occur. Empowerment in cancer survivorship results in many consequences including increased knowledge and communication (Earle, 2007), increased confidence in self-management and health promotion behaviors (Wiljer et al., 2013), and improved quality of life (Doyle, 2008).

\section{RELATED CONCEPTS}

Related concepts are "concepts that bear some relationship to the concept of interest but do not seem to share the same set of attributes" (Rodgers, 2000, p. 92). Concepts related to empowerment identified in the literature include control, awareness, and patient engagement.

\section{IDENTIFICATION OF AN EXEMPLAR}

An exemplar is provided to demonstrate how the concept of empowerment can be placed in a cancer survivorship context (Rodgers, 2000). Miller (2008) reports how her institution used survivorship care plans as a way to increase involvement of breast cancer survivors in their care. Consultations were held between a nurse and a survivor to construct a survivorship care plan within a few weeks of initial therapy completion. The nurse was involved in the development of the survivorship care plan because survivors had established a trusting and respectful relationship with the nurse throughout their treatment. The care plan served as a guide to teaching and provided the nurse and patient an opportunity to discuss a summary of the up-to-date treatment that the survivor received, recommended follow-up care, health promotion strategies, and contact information in case the patient had a question or concern. There was also a section that walked through an assessment of the 
survivor's psychosocial, employment, insurance, and financial issues. Focusing on the subjective concerns of survivors made the care plan patient centered and individualized and addressed the dynamic nature of empowerment. Survivors' autonomy was respected by providing the knowledge and skills necessary for survivors to make informed choices about their future treatment and health promotion. Power-with was demonstrated during qualitative interviews with the survivors after the consultations. Survivors reported that the consultations helped them understand their illness better and helped them recognize that they played an important role in the survivorship trajectory. The overwhelming feelings and confusion they felt prior to the consultation had dissipated and the survivors found the care plans beneficial to their future.

\section{DISCUSSION}

Given the prominence of the patient's experience of care and patient-centered outcomes within the Institute for Healthcare Improvement's (IHI) Triple Aim (IHI, 2012), it is important to uncover survivors' perspectives of the concept of empowerment so that those perspectives can help guide the development of interventions designed to improve the survivorship experience. This analysis demonstrated that although nurses and survivors may have a similar definition of the concept of empowerment, the uses and assumptions of that definition may differ. Although nurses may assume that empowerment is a nursing action provided to patients through sharing of information and support, survivors may perceive their internal resources as the source of empowerment. Nurses must also be careful not to use empowerment as a way to make survivors compliant with their goals; rather, nurses must meet with survivors and determine mutually agreed-upon goals. In addition, nurses may assume that survivors want to be either more or less involved in their care than they really do; therefore, survivors should be encouraged to share with nurses the extent to which they want to be involved in their care. Lastly, nurses must be educated about the benefits of delivering empowering care to survivors so that the perspective of empowerment being a burden to care is clarified.

The challenge of conducting a concept analysis of empowerment within the dual perspectives of cancer survivors and nurses was that there was more literature published from the expert or nurse perspective, creating a unidirectional view of empowerment. A second challenge was the limited amount of literature on empowerment in cancer survivorship, the context of interest for this analysis. Although empowerment has been shown to engage chronic illness patients in their care, few empowerment interventions have been used in cancer survivorship research to date, in part, because cancer as a chronic illness is a relatively new perspective. Despite these limitations, illuminating the attributes of an empowering nurse-survivor relationship creates future opportunities to study the process of empowerment empirically and link nurse behaviors to patient outcomes. Using both an evolutionary and dimensional analysis illuminated how survivors' and nurses' perspectives of the concept of empowerment in cancer survivorship may coincide and how they may differ. Presentation of an exemplar helped illustrate how an intervention might be developed that appeals to survivors' perceptions of the concept of empowerment within the context of cancer survivorship.

The attributes, along with the antecedents and consequences, provide a foundation for future theory and nurse intervention development. Future studies should be conducted measuring the effectiveness of an intervention that uses the components of the process of empowerment from survivors' perspectives. Nurses can use empowering behaviors as a way to develop survivorship care plans and 
build confidence in self-managing and health-promoting behaviors in cancer survivors to improve the care of comorbidities, disease-free survival rates, and functional declines in cancer survivors (DemarkWahnefried, Pinto, \& Gritz, 2006). One could hypothesize that helping cancer survivors realize that they have the right and capacity to make decisions about their care and actively involving them in their care through mutual goal setting and patient-centered education would increase the development of power-with. Power-with occurs when patients demonstrate the knowledge and skills necessary to take control of their health care and lead to consequences such as increased self-efficacy, self-esteem, perceived control, and higher quality of life.

Spence Laschinger et al. (2010) argue that empowering patients so that they are able to better manage their health is a central focus of nursing practice. Nurses and patients often work together to obtain information, resources, support, and opportunities for skill and knowledge development (Spence Laschinger et al., 2010) necessary for patients to become more involved in their care and exert more control over their health. Nurses play an essential role in advocating for patients (Zomorodi \& Foley, 2009) and therefore the process of patient empowerment is fundamental to the science of nursing (Spence Laschinger et al., 2010). Future research needs to be directed at measuring patientempowering nurse behaviors from the patient's perspective so that recommendations can be made for strengthening nurse-patient interactions to improve patient outcomes, measured as engagement in self-managing behaviors.

\section{CONCLUSION}

This dimensional and evolutionary concept analysis demonstrated how the concept of empowerment has been constructed over time from the differing perspectives of nurses and survivors and how it can be placed within the context of cancer survivorship. This combined analysis demonstrated the importance of assessing to what degree and how survivors want to participate in their care because the desire for autonomy can vary between survivors. Because of the complexity and life-threatening nature of a cancer diagnosis, survivors place heavy value on being able to trust their providers and feel empowered when they are able to gain control of even a little part of their lives by acquiring the ability to access information and support. Placing the concept of empowerment into the context of cancer survivorship guides nurses to move away from a paternalistic care approach to a more patientcentered model, consistent with numerous health care policies enacted by the Institute of Medicine (2001), National Priorities Partnership (2008), and the Commonwealth Fund (2009).

This concept analysis could be used to frame future research initiatives involving empowerment within the context of cancer survivorship. The identification of the attributes of the process of empowerment within the context of cancer survivorship provides a foundation for future theory development that could help frame an examination of the contribution of nursing care to the empowerment of cancer survivors. Empowerment is a patient-centric concept that can be examined within the patient-nurse relationship. Survivor perceptions of patient-empowering nurse behaviors could be further investigated using Spence Laschinger et al.'s (2010) framework for patient-empowering nurse behaviors based on Kanter's (1993) structural empowerment framework. This modified framework can be applied to nursing care of survivors because nurses work with their patients to make sure they have the knowledge and skills necessary to succeed, much like managers do with their employees. Patient- 
empowering nurse behaviors can be linked to patient outcomes using a wide range of theoretical research and practice models.

\section{REFERENCES}

R. M. Anderson, \& M. M. Funnell (2005). Patient empowerment: Reflections on the challenge of fostering the adoption of a new paradigm. Patient Education \& Counseling, 57(2), 153-157.

R. M. Anderson, \& M. M. Funnell (2010). Patient empowerment: Myths and misconceptions. Patient Education \& Counseling, 79(3), 277-282.

J. Anderson, M. Rainey, \& G. Eysenbach (2003). The impact of CyberHealthcare on the physicianpatient relationship. Journal of Medical Systems, 27, 67-84.

I. Aujoulat, W. d'Hoore, \& A. Deccache (2007). Patient empowerment in theory and practice: Polysemy or cacophony?Patient Education and Counseling, 66, 13-20.

Y. Bartlett, \& N. Coulson (2011). An investigation into the empowerment effects of using online support groups and how this affects health professional/patient communication. Patient Education \& Counseling, 83(1), 113-119.

M. Bjorklund, A. Sarvimaki, \& A. Berg (2008). Health promotion and empowerment from the perspective of individuals living with head and neck cancer. European Journal of Oncology Nursing, 12, 26-34.

C. Bradbury-Jones, S. Sambrook, \& F. Irvine (2008). Power and empowerment in nursing: A fourth theoretical approach. Journal of Advanced Nursing, 62(2), 258-266.

C. Bulsara, A. Ward, \& D. Joske (2004). Haematological cancer patients: achieving a sense of empowerment by use of strategies to control illness. Journal of Clinical Nursing, 13(2), 251-258.

C. Caron, \& B. Bowers (2000). Methods and application of dimensional analysis: A contribution to concept and knowledge development in nursing. In B. L. Rodgers \& K. A. Knafl (Eds.), Concept development in nursing: Foundations, techniques, and applications (pp. 285-319). Philadelphia, PA: Saunders.

M. Christensen, \& J. Hewitt-Taylor (2006). Modern nursing. Empowerment in nursing: Paternalism or maternalism? British Journal of Nursing, 15(13), 695-699.

The Commonwealth Fund. (2009). The path to a high performance U.S. health system: A 2020 vision and the policies to pave the way. Retrieved, from http://www.commonwealthfund.org/ /media/Files/Publications/Fund\%20Report/2009/Feb/T he\%20Path\%20to\%20a\%20High\%20Performance\%20US\%20Health\%20System/1237_Commissi on_path_high_perform_US_hlt_sys_WEB_rev_03052009.pdf

W. Demark-Wahnefried, B. Pinto, \& E. Gritz (2006). Promoting health and physical function among cancer survivors: Potential for prevention and questions that remain. Journal of Clinical Oncology, 24(32), 5125-5131.

N. Doyle (2008). Cancer survivorship: Evolutionary concept analysis. Journal of Advanced Nursing, 62(4), 499-509.

C. C. Earle (2007). Long term care planning for cancer survivors: A health services research agenda. Journal of Cancer Survivorship, 1, 64-74.

C. C. Ellis-Stoll, \& S. Popkess-Vawter (1998). A concept analysis on the process of empowerment. Advances in Nursing Science, 21(2), 62-68.

R. M. Epstein, K. Fiscella, C. S. Lesser, \& K. C. Stange (2010). Why the nation needs a policy push on patient-centered health care. Health Affairs, 29, 1489-1495.

A. R. Falk-Rafael (2001). Empowerment as a process of evolving consciousness: A model of empowered caring. Advances in Nursing Science, 24(1), 1-16. 
B. J. Farmer, \& E. D. Smith (2002). Breast cancer survivorship: Are African American women considered? A concept analysis. Oncology Nursing Forum, 29(5), 779-787.

M. Faulkner (2001). Empowerment, disempowerment and the care of older people. Nursing Older People, 13(5), 18-20.

D. L. Finfgeld (2004). Empowerment of individuals with enduring mental health problems: Results from concept analyses and qualitative investigations. Advances in Nursing Science, 27(1), 44-52.

M. Foucault, \& C. Gordon (1980). Power/knowledge: Selected interviews \& other writings 1972-1977. New York, NY: Pantheon Books.

M. M. Funnell, \& R. M. Anderson (2003). Professional development. Patient empowerment: A look back, a look ahead. Diabetes Educator, 29(3), 154-164.

P. A. Ganz (2009). Quality of care and cancer survivorship: The challenge of implementing the Institute of Medicine recommendations. Journal of Oncology Practice, 5(3), 101-105.

C. M. Gaston, \& G. Mitchell (2005). Information giving and decision-making in patients with advanced cancer: A systematic review. Social Science \& Medicine, 61(10), 2252-2264.

C. H. Gibson (1991). A concept analysis of empowerment. Journal of Advanced Nursing, 16(3), 344361.

T. L. Hagan, \& H. S. Donovan (2013). Ovarian cancer survivors' experiences of self-advocacy: A focus group study. Oncology Nursing Forum, 40(2), 140-147.

J. Hawks (1992). Empowerment in nursing education: Concept analysis and application to philosophy, learning and instruction. Journal of Advanced Nursing, 17(5), 609-618.

M. Hewitt, S. Greenfield, \& E. Stovall (Eds.). (2005). From cancer patient to cancer survivor: Lost in transition. Washington, DC: National Academies Press.

I. Holmstrom, \& M. Roing (2009). The relation between patient-centeredness and patient empowerment: A discussion on concepts. Patient Education and Counseling, 79(2), 167-172.

Improving Chronic Illness Care. (2012). The chronic care model: Model elements. Retrieved from http://www.improvingchroniccare.org/index.php?p=Model_Elements\&s=18

Institute for Healthcare Improvement. (2012). The IHI Triple Aim. Retrieved from http://www.ihi.org/offerings/initiatives/tripleaim/pages/default.aspx

Institute of Medicine. (2001). Crossing the quality chasm: A new health system for the 21st century. Washington, DC: National Academies Press.

M. Irwin, J. R. Klemp, C. Glennon, \& L. M. Frazier (2011). Oncology nurses' perspectives on the state of cancer survivorship care: Current practice and barriers to implementation. Oncology Nursing Forum, 38(1), E11-E19.

M. O. Johnson (2011). The shifting landscape of health care: Toward a model of health care empowerment. American Journal of Public Health, 101(2), 265-270.

B. Johnston, \& L. N. Smith (2006). Nurses' and patients' perceptions of expert palliative nursing care. Journal of Advanced Nursing, 54(6), 700-709.

N. C. Kaiser, N. Hartoonian, \& J. E. Owen (2010). Toward a cancer-specific model of psychological distress: Population data from the 2003-2005 National Health Interview Surveys. Journal of Cancer Survivors, 4, 291-302.

R. M. Kanter (1993). Men and women of the corporation. New York, NY: Basic Books.

R. M. Kaplan, \& D. L. Frosch (2005). Decision making in medicine and health care. Annual Reviews of Clinical Psychology, 1, 525-556.

J. Kawi (2012). Self-management support in chronic illness care: A concept analysis. Research and Theory for Nursing Practice, 26(2), 108-125. 
S. C. Kim, D. Boren, \& S. L. Solem (2001). The Kim Alliance Scale: Development and preliminary testing. Clinical Nursing Research, 10, 314-331.

G. Laverack (2007). Health promotion practice: Building empowered communities. Maidenhead, United Kingdom: Open University Press.

D. Lewin, \& S. Piper (2007). Patient empowerment within a coronary care unit: Insights for health professionals drawn from a patient satisfaction survey. Intensive and Critical Care Nursing, 23(2), 81-90.

M. Little, E. Sayers, K. Paul, \& C. F. C. Jordens (2000). On surviving cancer. Journal of the Royal Society of Medicine, 93(10), 501-503.

J. E. Liu, E. Mok, \& T. Wong (2006). Caring in nursing: Investigating the meaning of caring from the perspective of cancer patients in Beijing, China. Journal of Clinical Nursing, 15(2), 188-196.

K. Malterud (2010). Power inequalities in health care-Empowerment revisited. Patient Education and Counseling, 79(2), 139-140.

T. J. Marbach, \& J. Griffie (2011). Patient preferences concerning treatment plans, survivorship care plans, education, and support services. Oncology Nursing Forum, 38(3), 335-342.

V. McCarthy, \& L. Freeman (2008). A multidisciplinary concept analysis of empowerment: Implications for nursing. Journal of Theory Construction \& Testing, 12(2), 68-74.

R. McCorkle, E. Ercolano, M. Lazenby, D. Schulman-Green, L. S. Schilling, K. Lorig, ... E. H. Wagner (2011). Self-management: Enabling and empowering patients living with cancer as a chronic illness. CA: A Cancer Journal for Clinicians, 61(1), 50-62.

N. Mendick, B. Young, C. Holcombe, \& P. Salmon (2010). The ethics of responsibility and ownership in decision-making about treatment for breast cancer: Triangulation of consultation with patient and surgeon perspectives. Social Science and Medicine, 20(12), 1904-1911.

C. Meyer, A. Muhlfeld, C. Drexhage, J. Floege, E. Goepel, P. Schauerte, . . T. Rassaf (2008). Clinical research for patient empowerment-A qualitative approach on the improvement of heart health promotion in chronic illness. Medical Science Monitor, 14(7), CR358-CR365.

R. Miller (2008). Implementing a survivorship care plan for patients with breast cancer. Clinical Journal of Oncology Nursing, 12(3), 479-487.

H. N. Mo, D. W. Shin, J. H. Woo, J. Y. Choi, J. Kang, Y. J. Baik, . . S. H. Cho (2012). Is patient autonomy a critical determinant of quality of life in Korea? End-of-life decision making from the perspective of the patient. Palliative Medicine, 26(3), 222-231.

E. Mok (2001). Empowerment of cancer patients: From a Chinese perspective. Nursing Ethics, 8, 69-76.

M. A. Morgan (2009). Cancer survivorship: History, quality-of-life issues, and the evolving multidisciplinary approach to implementation of cancer survivorship care plans. Oncology Nursing Forum, 36(4), 429-436.

National Coalition for Cancer Survivorship. (2006). Teamwork: The cancer patient's guide to talking with your doctor. Retrieved from http://www.canceradvocacy.org/resources/publications/teamwork.pdf

National Coalition for Cancer Survivorship. (2010). The organization. Retrieved from http://www.canceradvocacy.org/about/org/

National Coalition for Cancer Survivorship. (2011). Defining terms. Retrieved from http://www.canceradvocacy.org/resources/take-charge/defining-terms.html

National Institutes of Health. (2011). Reducing chronic diseases must be a global priority. Retrieved from http://www.nhlbi.nih.gov/about/globalhealth/

National Priorities Partnership. (2008). National priorities and goals: Aligning our efforts to transform America's healthcare. Washington, DC: National Quality Forum. 
L. Nyatanga, \& K. Dann (2002). 'Empowerment in nursing: The role of philosophical and psychological factors.'Nursing Philosophy, 3(3), 234-239.

S. Payne (2007). Living with advanced cancer. In M. Feuerstein (Ed.), Handbook of cancer survivorship (pp. 429-446). New York, NY: Springer.

S. Peck (2008). Survivorship: A concept analysis. Nursing Forum, 43(2), 91-102.

L. Pedro (2001). Quality of life for long-term survivors of cancer: Influencing variables. Cancer Nursing, 24(1), 1-11.

J. Rappaport (1984). Studies in empowerment: Introduction to the issue. Prevention in Human Services, 3, 1-7.

C. Rissel (1994). Empowerment: The holy grail of health promotion?Health Promotion International, 9(1), 39-47.

B. I. Rodgers (1989). Concepts, analysis and the development of nursing knowledge: The evolutionary cycle. Journal of Advanced Nursing, 14(4), 330-335.

B. I. Rodgers (2000). Concept analysis: An evolutionary view. In B. L. Rodgers \& K. A. Knafl (Eds.). Concept development in nursing: Foundations, techniques, and applications (pp. 77-102). Philadelphia, PA: Saunders.

C. M. Rodwell (1996). An analysis of the concept of empowerment. Journal of Advanced Nursing, 23, 305-313.

S. Ryles (1999). A concept analysis of empowerment: Its relationship to mental health nursing. Journal of Advanced Nursing, 29(3), 600-607.

C. Sainio, E. Eriksson, \& S. Lauri (2001). Patient participation in decision making about care-The cancer patient's point of view. Cancer Nursing, 24(3), 172-179.

E. J. Shepherd, \& R. L. Woodgate (2010). Cancer survivorship in children and young adults: A concept analysis. Journal of Pediatric Oncology Nursing, 27(2), 109-118.

C. Sinding, P. Hudak, J. Wiernikowski, J. Aronson, P. Miller, J. Gould, . . D. Fitzpatrick-Lewis (2010). “I like to be an informed person but ..." negotiating responsibility for treatment decisions in cancer care. Social Science and Medicine, 71(6), 1094-1101.

H. K. Spence Laschinger, S. Gilbert, L. M. Smith, \& K. Leslie (2010). Towards a comprehensive theory of nurse/patient empowerment: Applying Kanter's empowerment theory to patient care. Journal of Nursing Management, 18(1), 4-13.

K. Stajduhar, L. Funk, E. Jakobsson, \& J. Ohlén (2010). A critical analysis of health promotion and 'empowerment' in the context of palliative family care-giving. Nursing Inquiry, 17(3), 221-230.

I. Stang, \& M. B. Mittelmark (2010). Intervention to enhance empowerment in breast cancer self-help groups. Nursing Inquiry, 17(1), 47-57.

P. Tengland (2008). Empowerment: A conceptual discussion. Health Care Analysis, 16, 77-96.

S. Tveiten, \& I. Meyer (2009). 'Easier said than done': Empowering dialogues with patients at the pain clinic-The health professionals' perspective. Journal of Nursing Management, 17(7), 804-812.

M. Twomey (2012). Autonomy and reason: Treatment choice in breast cancer. Journal of Evaluation in Clinical Practice, 18, 1045-1050.

C. F. van Uden-Kraan, C. H. Drossaert, E. Taal, E. R. Seydel, \& M. A. van de Laar (2009). Participation in online patient support groups endorses patients' empowerment. Patient Education and Counseling, 74, 61-69.

D. Victorson, D. Cella, L. Wagner, L. Kramer, \& M. L. Smith (2007). Measuring quality of life in cancer survivors. In M. Feuerstein (Ed.), Handbook of cancer survivorship (pp. 79-110). New York, NY: Springer. 
H. Virtanen, H. Leino-Kilpi, \& S. Salanterä (2007). Empowering discourse in patient education. Patient Education \& Counseling, 66(2), 140-146.

D. Wiljer, S. Urowitz, J. Jones, A. Kornblum, S. Secord, \& P. Catton (2013). Exploring the use of the survivorship consult in providing survivorship care. Supportive Care in Cancer, 21(8), 21172124. http://0-dx.doi.org.libus.csd.mu.edu/10.1007/s00520-013-1760-4

World Health Organization. (2009). Milestones in health promotion: Statements from global conferences. Retrieved from http://www.who.int/healthpromotion/Milestones_Health_Promotion_05022010.pdf

M. Zomorodi, \& B. J. Foley (2009). The nature of advocacy vs. paternalism in nursing: Clarifying the 'thin line.'Journal of Advanced Nursing, 65(8), 1746-1752. 